ON THE CURATIVE EFFECTS OF MILK DIET. By GEORGE THIN, M.D.

IT has been long known that many cases of intestinal derangement produced by various causes recover under exclusive milk diet, but the rationale of the improvement that takes place in these cases has perhaps not been sufficiently studied; and the possible curative effect of milk diet in diseases which, although not attended by an obtrusively irritated condition of the intestine, may yet be caused by abnormal products of digestion, and in which the treatment has not been yet tried, is a subject which well deserves further experimental investigation.

My own experience of the curative effect of milk diet dates from 1879 , when I prescribed it with success in a case of psilosis of extreme gravity, which, until milk was used, had got progressively worse under much and long treatment by drugs and diet. An account of my subsequent experiences of the value of this treatment was contributed to the Prac. titioner in 1883 , and afterwards reprinted in pamphlet form. Further contributions to the subject were published in the British Medical Journal, July 8th, 1893 , and February 9 th, 1895. A more complete account of the value of milk diet in psilosis and dysentery, the method of administration, and the precautions that require to be taken, will be found in the second edition of my work on psilosis, ${ }^{1}$ which has just been published. Those who are specially interested in the subject of milk diet, as well as in the treatment of psilosis, I refer to Chapter viii in that book for many details for which it is impossible to find space here.

It is my present purpose to utilise a case which has recently been und r my observation in order to show how the health of a very weak patient may suddenly improve when nutritious articles of diet are withdrawn and exclusive milk diet substituted, the condition of the nails in this patient affording a striking object lesson of the poisonous effects of usually wholesome food in deranged conditions of the intestinal canal. I have attempted to show in my book that cases of psilosis may be grouped into two distinct varieties, one being the "psilosis linguæ et mucosæ intestini" (the "sprue" of the Dutch of Java), the other being examples of intestinal psilosis described by Indian writers as diarrhœa alba, white flux, etc. I have at page 252 of the work referred to described this patient's case as an example of the Indian diarrhœea alba.

The patient, a somewhat delicate but healthy man, visited India when he was 30 years of age, twelve years before I saw him. He was only two months in India, and whilst there had a sharp attack of diarrhoa, which lasted a few days. After returning to England he was subject to great drowsiness, and, six months after he came home, he began to find that certain kinds of food produced retching, pain in the bowels, and diarrhcea, attended by high temperature. For eleven years he was much dieted by his medical advisers, and found that he did best when he ayoided fibrous vegetables, and lived on mutton chops, game, and such liize food. During the several years in which he lived on this diet he continued to suffer more or less, the motions being copious, soft, colourless, and acid. His general health deteriorated, and symptoms of malnutrition of the nervous system began to appear, but temporary improvement followed a short sea voyage and change of climate, On returning to England his symptoms became worse than they had ever been. In addition to certain drugs a liberal diet of strong beef tea, meat three times a day, and alcoholic stimulants were prescribed, with bad results, all his symptoms, particularly those connocted with the nervous system, becoming aggravated. He was then sent away from home for a change, and the physician under whose care he was placed prescribed exclusive milk diet, and this was the first treatment, I was informed, which had any beneficial results.

Six months after this I saw him for the first time. He had not been on strict milk diet for some time, but, as he was still passing two large, unformed motions daily, I enjoined once more an exclusive milk diet, with rest and warmth, and there was speedy improvement in the motions. As the case is still under observation, I shall not, at present, describejit further. On examining the patient, I was much struck with the condi- tion of the nails. I found that in the nails of both hands the anterior half of each nail consisted of a broken-down, granular, uneven mass, whilst the pnsterior half presented a healthy appearance. On inquiring into the history of this condition, I was informed that when he began milk treatment,

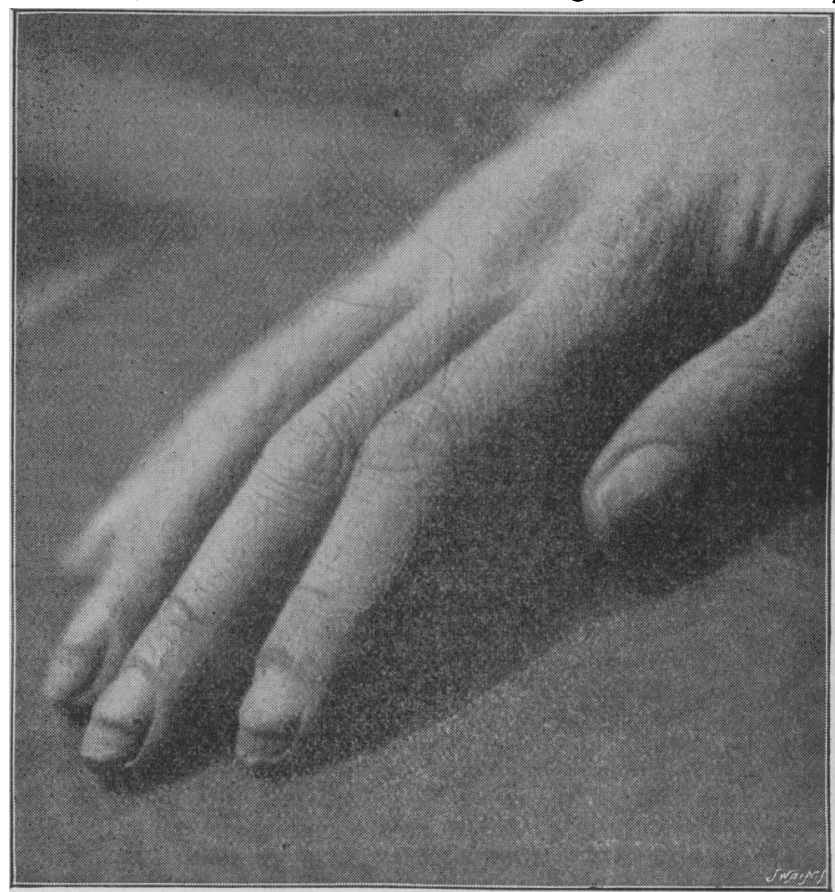

six months before, the whole of the nalls was in the diseased condition now shown by the anterior halves, but from the time that the milk dipt was commenced the new growth of nail began to be healıhy. The condition when I saw him

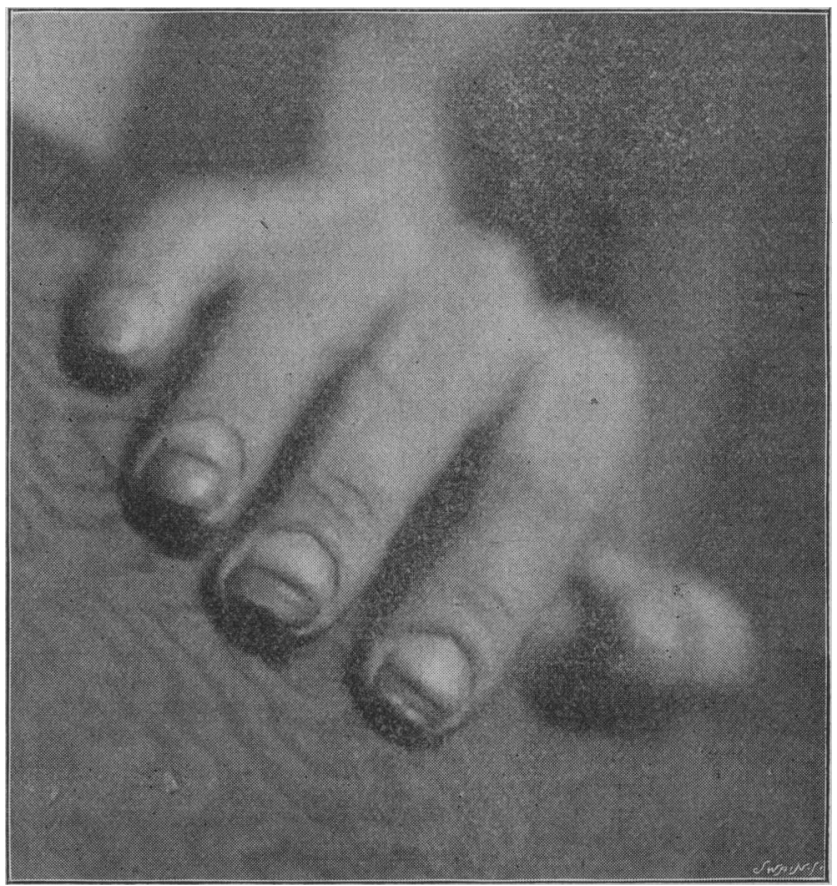

is fairly well shown in the accumpanylny illurtrations, which have been rer $r$ luced from photographs which he was ind enough to have taken for me within a week after I saw him. 
Thís description of the case has been given, and the illustrations have been added to it, in order to direct attention to the fact that in certain morbid conditions of the intestinal mucous membrane the ingestion of nutritious articles of diet may not only lead to a continuance of the intestinal symptoms, but may have a special bad effect on the nutrition of some parts of the body which should not be ascribed to simple starvation, but which, in my opinion, is due to some unknown poison generated in the intestinal canal. In this man's case the cerebro-spinal nervous system, and the growth of the horny epithelium from which the nails are built up, were specially affected by this poison. (As a matter of subsidiary interest, it may be noted that the length of good nail shown in the illustrations represents six months' growth).

In connection with the modus operandi of milk diet in these cases the question suggests itself, Is it the milk that cures the disease, or does the disease get well because the other foods which the patient was taking are excluded? I have frequently observed that patients suffering from psilosis, and who have been doing well on exclusive milk diet for wf ek? experience a severe relapse as soon as a raw or lightly koiled egg is taken, or a cupful of arrowroot given. In such cases the relapse could not be due to any mechanical irritation produced by the egg or arrowroot, and I can only infer that it is caused by those substances constituting a pabulum for the development of some form of fermentation which does not occur when milk alone is given. I infer that an active cause of some abnormal fermentation can develop in eggs and arrowroot, beef tea, etc., but cannot grow in milk or its products during digestion.

In all cases of psilosis there is evidence of much abnormal fermentation in the intestinal canal. In this disease the fluid fæces are often so charged with gases as to cause the surface of the motion to be covered with air bubbles, the fermentation continuing for some time after they have been passed. A small (I ounce) bottle of semi-liquid fæces was recently sent to me for microscopical examination, the stopper being firmly tied down with string. On cutting the string the pressure of the gas that had be en evolved after the stopper was fastened was so great, that it was ejected with violence, with a sound like that caused by the ejection of the cork of a gingerbeer bottle when the wire is incautiously undone.

The anæmia in psilosis, as I have shown in greater length and detail in my book, is probably due to the effect of some poison associated with the abnormal fermentation. It is sometimes so great that I have known a case of true psilosis diagnosed by a distinguished physician as one of essential pernicious ânæmia. That the anæmia is not due so much to defective nutrition as to the destructive effect on the blood formation caused by the absorption of the poisonous product of fermentation in the intestine, is shown by the rapid improvement that takes place in the number of the red corpuscles when all food is withdrawn except a small amount of milk. In this connection I may refer to the opinion expressed by the late Sir Andrew Clark, ${ }^{2}$ that the anæmia of young women in chlorosis is due to a functional derangement of the intestinal canal, and should be treated by purgatives.

There are other diseases which are probably due to a similar cause. Gout, for example, so common and yet so little understood, is clearly associated with some persistent error in digestion, and if some physician whose opportunities are sufficient were bold enough to treat a series of cases of gout by exclusive milk diet, it would be of great interest to know the result.

I was much struck a number of years ago by the effect of an exclusive milk diet in a severe and fully-developed case of lupus erythematosus, which had been under my care. A woman, in the prime of life, had the fully-developed batwing form of the disease, the nose and both cheeks being affected, and during the few months that she was under my care did not materially improve. She disappeared from my observation, and when I next saw her (a considerable time afterwards) the disease bad entirely disappeared and the skin was healthy. On inquiring how this had happened, she told me that she had developed some serious abdominal (as I understood her, uterine) affection, for which a physician in Glasgow put her in bed and on exclusive milk diet, and whilst she was under this treatment the lupus erythematosus gradually faded, and eventually disappeared and never returned. I need hardly say that I prescribed the milk treatment for subsequent cases of lupus erythematosus, but unfortunately never again observed the same curative effect.

1 Psilosis or "Sprue": its Nature and Treatment: $w^{\text {th }}$ 'Observations on Various forms of Diarrhoa acquired in the Tropics. Second and enlarged edition. London: J. and A. Churchill. r897. 2 BRITISH MEDICAL JoURNsL, November igth, r887, pp. Iro6. Report of a meeting of the Medical Society of London.

\section{NOTES ON A CASE OF ACROMEGALY.}

BY JOHN NORCOTT D'ESTERRE, M.R.C.S., L.R.C.P., Eastbourne.

J.H., male, aged 39 , married; has four children, who are all healthy. His family history is good, and there is no history of a similar complaint in the family. His personal history also is good; he never had any illness until seven Jears ago, when he had an attack of influenza, after which he noticed his nnder lip and tongue swelling, and his hands and chest enlarging.

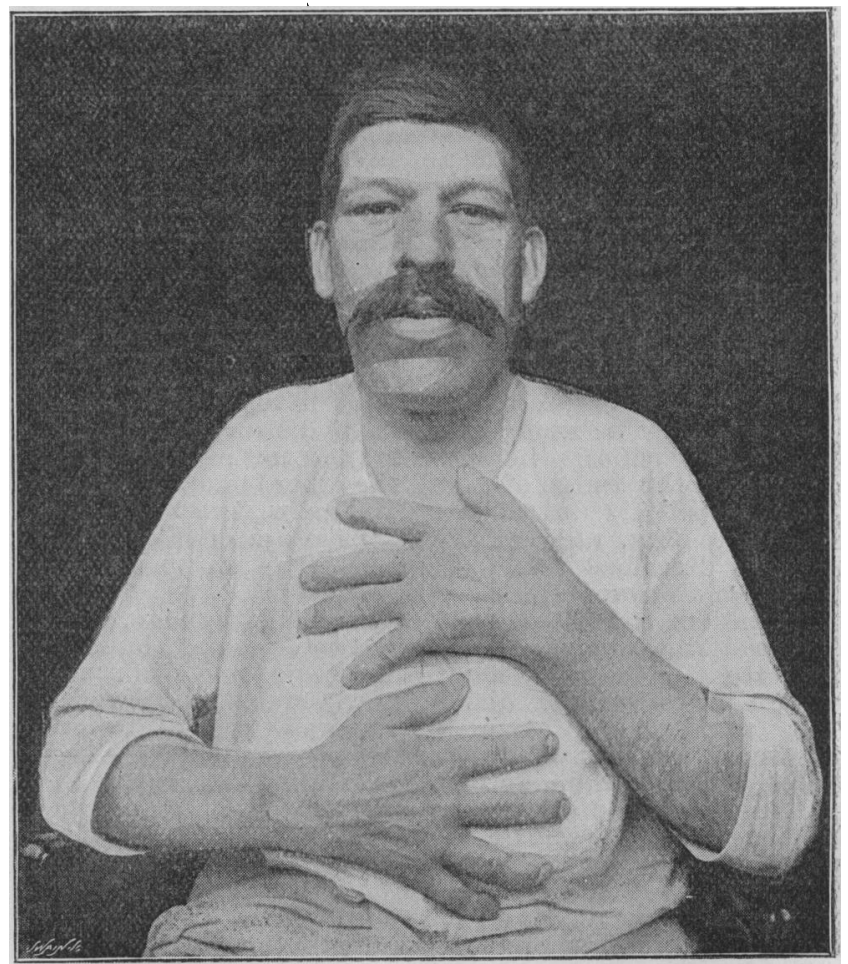

1 first saw mun on dugust 24lh, 1897 , when 1 fuund that he was a well-nourished man with ponderous and large hands, and that his feet also were larger than normal, but not to such a degree as the hands. His features were heavy, with a very large, thick, projecting under lip, massive underjaw (due to bony growth, and not to any subcutaneous deposit); the teeth of the lower jaw projected in front of those in the upper, and were spreading. The cartilages of the nose and ears were greatly thickened, and probably those of the larynx, as his voice, he informed me, had altered of late to a deep bass. He had prominent frontal eminences, with deep hollows in both temporal fosex. The skin of the face was slightly pigmented, the orifices of sweat glands enlarged. The senses of smell, taste, and hearing were good. The tongue was enormously enlarged, so much so that when he opened his mouth it appeared to fill the entire cavity. The tonsils and uvula were also enlarged. He complained of difficulty in swallowing at times, and of slight asthmatic seizures. In form the face was ovoid. His eyesight was getting woree, and 